\title{
Efeito alelopático do extrato aquoso de folhas de girassol sobre a germinação de soja e picão-preto
}

\section{Allelopathic effect of sunflower water extract on the germination of soybean and hairy beggartick}

\author{
Jaqueline Malagutti Corsato ${ }^{1 *}$; Andréa Maria Teixeira Fortes ${ }^{2}$; \\ Márcia Santorum ${ }^{3}$; Raquel Leszczynski ${ }^{4}$
}

\begin{abstract}
Resumo
O objetivo deste trabalho foi avaliar o efeito alelopático do extrato aquoso de folhas frescas de girassol sobre a germinação das sementes e desenvolvimento inicial das plântulas das cultivares de soja (Glycine $\max (\mathrm{L}$.$) Merrill) convencional (CD232), transgênica (CD213RR) e uma de suas invasoras, o picão$ preto (Bidens pilosa L.). Os experimentos foram realizados no Laboratório de Fisiologia Vegetal da Universidade Estadual do Oeste do Paraná no ano de 2007. As folhas de girassol colhidas na época da floração foram trituradas com o auxílio de um liquidificador na proporção de $200 \mathrm{~g} / 1 \mathrm{~L}$ de água destilada resultando no extrato bruto (100\%). A partir do extrato bruto foram feitas as diluições de $80 \%, 60 \%$, $40 \%$ e $20 \%$, sendo utilizado como testemunha apenas água destilada. Após análise estatística (Tukey 5\% de probabilidade), pode-se verificar que o extrato aquoso das folhas de girassol influenciou as variáveis analisadas para a soja cultivares CD323 e CD213RR, principalmente nas concentrações de $60 \%, 80 \%$ e $100 \%$. As sementes de picão preto tiveram a porcentagem de germinação totalmente inibida quando aplicado o extrato aquoso a $40 \%$, indicando que a palhada de girassol poderia servir como um herbicida natural, porém estudos em condições de campo devem ser realizados para a comprovação deste efeito. Palavras-chave: Helianthus annus L, alelopatia, Glycine max (L.) Merrill, Bidens pilosa L.
\end{abstract}

\begin{abstract}
The aim of this work was to evaluate the allelopathic effect of water extract from sunflower fresh leaves on the germination and initial development of conventional and transgenic soybean cultivars, and of the invasive hairy beggartick (Bidens pilosa L.). Experiments were carried out at Laboratory of Plant Physiology, Universidade Estadual do Oeste do Paraná, in 2007. Fresh leaves from sunflower were ground in a blender at the proportion $200 \mathrm{~g} / 1 \mathrm{~L}$ distilled water, resulting in crude extract $(100 \%)$, in which pH was measured. Dilutions of $80 \%, 60 \%, 40 \%$ and $20 \%$ were done from the crude extract, and only distilled water was used as control. Statistical analysis (Tukey $5 \%$ probability) indicated that only the highest extract concentrations $(60 \%, 80 \%$ and $100 \%)$ influenced the analyzed parameters for conventional and transgenic soybean. Beggartick seeds, however, had germination percentage completely inhibited when $40 \%$ water extract was applied, which indicates that sunflower straw could be used as a natural herbicide. Nevertheless, field studies must be carried out to prove such effect.

Key words: Helianthus annus L., allelopathy, Glycine max (L.) Merrill, Bidens pilosa L.
\end{abstract}

1 Biológa, Doutoranda do Curso de Ciências Biológicas - Botânica da Universidade Estadual Paulista "Júlio de Mesquita Filho" - UNESP Campus Botucatu, Sp. Telefone: (14) 38116265. E-mail: jaque_corsato@hotmail.com

2 Bióloga, Dr., Professora adjunta do curso de Ciências Biológicas da Universidade Estadual do Oeste do Paraná - UNIOESTE Campus Cascavel, Pr. E-mail: amtfortes@unioeste.br

3 Bióloga, Mestranda do Curso de Engenharia Agrícola da Universidade Estadual do Oeste do Paraná - UNIOESTE Campus Cascavel, Pr.. E-mail: mar_santorum@hotmail.com

4 Bióloga, Mestranda do Curso de Genética e Melhoramento da Universidade de Maringá - UEM Campus Maringá, Pr. E-mail: raquelleszczynsk@hotmail.com

* Autor para correspondência 


\section{Introdução}

O uso de espécies vegetais para compor sistemas de manejo do solo tornou-se comum após a "revolução verde" e dentre as práticas de manejo mais utilizadas pode-se citar o plantio direto, que procura reduzir o excesso de mecanização e manter as condições do solo favoráveis ao plantio (PRIMAVESI, 1986). De maneira geral, esta técnica consiste na manutenção da cobertura vegetal sobre o solo, permitindo a conservação da bioestrutura e o equilíbrio do mesmo. Porém, a produção de matéria seca e sua manutenção sobre o solo é a principal dificuldade a ser superada para o bom desenvolvimento do plantio direto (PRIMAVESI, 2003; EMBRAPA RORAIMA, 2005).

Associada a técnica de plantio direto, a alternância anual de espécies vegetais em áreas agrícolas apresenta-se como um método de baixo custo para o controle de doenças de final de ciclo, principalmente do cultivo de soja, constituindo assim um incentivo aos agricultores para o desenvolvimento desta técnica de manejo do solo (HOFFMANN et al., 2004).

A rotação de culturas pode exercer controle sobre insetos e plantas invasoras das culturas comerciais, através da alelopatia ou competição, reduzindo a quantidade de herbicidas e pesticidas utilizados nas lavouras além de contribuir para minimizar os impactos ambientais gerados com o advento de práticas agrícolas intensivas (CARVALHO, 2006).

Dessa forma, uma maneira alternativa para o controle de plantas invasoras em agrossistemas pode ser o emprego de espécies vegetais com potencial alelopático para compor os sistemas de manejo das propriedades agrícolas (ALMEIDA, 1991).

A alelopatia é um efeito que pode ser verificado sobre todos os organismos, porém, nos vegetais ele torna-se mais evidente. Rice (1984) redefiniu o termo alelopatia, como qualquer efeito direto ou indireto, benéfico ou prejudicial de uma planta ou microorganismo sobre outra planta, mediante a produção de compostos químicos liberados no ambiente (FERREIA; AQUILA, 2000; ALMEIDA, 1991).

Estes compostos liberados no ambiente são denominados de aleloquímicos ou metabólitos secundários. Cada espécie vegetal pode sintetizar mais de um tipo de metabólito secundário (WITTAKER, 1970; WCKNER, 1972 citado por CARMO; FERREIRA, 2004). Dentre os metabólitos secundários mais conhecidos, estão as substâncias pertencentes ao grupo dos ácidos fenólicos, cumarinas, terpenóides, flavonóides, alcalóides, glicosídeos cianogênicos, derivados do ácido benzóico, taninos e quinonas complexas (MONTEIRO; VIEIRA, 2002; ALMEIDA, 1988).

Quanto ao modo de ação, as substâncias alelopáticas podem agir sobre o crescimento, desenvolvimento e na germinação de sementes de muitas espécies. A germinação é um dos processos menos sensíveis à ação dos aleloquímicos, enquanto o desenvolvimento inicial da raiz primária, normalmente em testes laboratoriais é a variável mais sensível, podendo ser beneficiada ou prejudicada (FERREIRA; AQUILA, 2000).

O girassol (Helianthus annus L.) é exemplo de espécie vegetal que pode ser empregada em técnicas de manejo que visem à formação de cobertura vegetal para a realização do plantio direto (PELEGRINI, 1985). Esta espécie é bem adaptada a diversos ambientes, resistindo a baixas temperaturas e estresse hídrico, diferentemente da maioria das espécies vegetais cultivadas no país (CASTRO et al., 1997).

Pasqualeto et al. (2007) notou, em estudos desenvolvidos no campo, que espécies vegetais infestantes à cultura de soja, podem ser reduzidas quando o girassol for cultivado antes da soja e concluiu que esta redução pode ter ocorrido pela interferência física ou alelopática desenvolvida pela palhada do girassol deixada sobre o solo.

Quanto ao efeito alelopático exercido pelo girassol sobre outras espécies vegetais, sabe-se que esta espécie possui a habilidade de inibir o 
crescimento de certos vegetais como mostarda (Sinapis alba L.), trigo (Triticum spp.) e invasores dependendo da variedade e da concentração das substâncias alelopáticas no meio (BHOWMIK; INDERJIT, 2003).

É comum encontrar nas diversas variedades de girassol metabólitos secundários como fenóis e terpenos, substâncias que apresentam funções importantes nos vegetais, que podem agir como compostos de defesa contra insetos, herbívoros e fungos, além, de limitar o crescimento de outras plantas no solo (KUPIDLOWSKA et al., 2006; TAIZ; ZEIGER, 2009).

Assim, torna-se possível o uso do girassol como vegetal de cobertura, sendo uma estratégia alternativa para o manejo de espécies vegetais invasoras, principalmente na agricultura orgânica. Entretanto, alguns estudos demonstram esta mesma atividade alelopática inibitória do girassol sobre espécies vegetais cultivadas como a mostarda (Sinapis alba L.), trigo (Triticum spp.), sorgo (Sorghum bicolor L. Moench), ressaltando a importância de mais estudos quanto à fitotoxidade do girassol para sua indicação em sistemas de rotação e sucessão de culturas (KUPIDLOWSKA et al., 2006; BERNAT et al., 2004).

O objetivo deste trabalho foi avaliar o efeito alelopático exercido pelo extrato aquoso de folhas verdes de girassol sobre a germinação das sementes e desenvolvimento inicial de plântulas de duas cultivares de soja (Glycine max (L.) Merrill), CD232 e CD213RR, e sobre uma de suas invasoras, o picão preto (Bidens pilosa L.).

\section{Material e Métodos}

O experimento foi conduzido no Laboratório de Fisiologia Vegetal da Universidade Estadual do Oeste do Paraná - UNIOESTE, localizado no Campus de Cascavel/PR, no ano de 2007. Para a obtenção do extrato aquoso, folhas verdes de girassol colhidas na época de floração foram trituradas com o auxílio de um liquidificador na proporção de $200 \mathrm{~g}$ de folhas para 1L de água destilada, resultando no extrato aquoso bruto (100\%). A partir do extrato bruto foram realizadas as diluições de $80 \%, 60 \%$, $40 \%$ e $20 \%$, sendo a água destilada utilizada como testemunha, resultando em seis tratamentos.

Uma amostra do extrato bruto (100\%) foi utilizada para a medição do $\mathrm{pH}$ (potencial hidrogeniônico) do mesmo, com o auxílio de um medidor de $\mathrm{pH}$. Foi realizada a medição apenas do extrato bruto, pois as diluições dos extratos foram realizadas em água destilada, a qual não interfere na mudança dos valores do $\mathrm{pH}$.

Para a germinação das sementes de soja foram utilizadas quatro repetições de 50 sementes por parcela acondicionadas em folhas de papel "Germiteste". As sementes de picão preto foram acondicionadas em placas de petri contendo duas folhas de papel filtro na base e uma sobre as sementes totalizando quatro repetições de 25 sementes por parcela.

Antes da instalação do experimento, os papéis para germinação e as placas de petri foram previamente autoclavados a temperatura de $121^{\circ} \mathrm{C} \pm$ $2^{\circ} \mathrm{C}$ por 20 minutos e posteriormente acondicionados em estufa de secagem, com temperatura entre $50^{\circ} \mathrm{C}$ $\pm 3^{\circ} \mathrm{C}$ e $100^{\circ} \mathrm{C} \pm 3^{\circ} \mathrm{C}$.

Durante a manipulação dos materiais as mãos e as bancadas passaram por um processo de assepsia com o uso de soluções bactericida (Lysoform 10\%) e fungicida (Nistatina 10\%). Para umedecer as três folhas de papel filtro contidas nas placas de petri, foi utilizado $10 \mathrm{ml}$ de água destilada ou extrato aquoso, enquanto foram usadas três folhas de papel 'germiteste' umedecidas na proporção de duas vezes e meia o peso do papel (BRASIL, 1992).

Para evitar a proliferação de fungos durante a realização dos experimentos, $1 \%$ da solução de Nistatina, foi adicionada nos papéis "Germiteste". Os experimentos foram acondicionados em câmara de germinação com fotoperíodo de 12 horas de 
claro e 12 horas de escuro e temperatura controlada a $25^{\circ} \mathrm{C} \pm 3^{\circ} \mathrm{C}$.

Para a soja, o delineamento experimental utilizado foi inteiramente casualizado, sendo o experimento com as variedades de soja, realizado em esquema fatorial 6x2 (seis concentrações do extrato x duas cultivar de soja). As avaliações foram realizadas diariamente, iniciando no dia seguinte a semeadura, sendo considerada como semente germinada aquela que apresentou $2 \mathrm{~mm}$ ou mais de raiz primária (HADAS, 1976). Para o picão preto o delineamento experimental foi inteiramente casualizado.

As variáveis analisadas foram porcentagem de germinação (PG\%), tempo médio de germinação (TMG) segundo Edmond e Drapala (1958), velocidade média de germinação (VMG) segundo Laboriau (1983) e comprimento médio da raiz primária (CMR). Os dados foram submetidos à análise de variância (teste F). Para a variável porcentagem de germinação foi necessária a utilização da transformação arco seno da raiz quadrada de x/100 (PIMENTEL-GOMES, 1990), sendo as médias comparadas pelo teste de Tukey a $5 \%$ probabilidade.

\section{Resultados e Discussão}

$\mathrm{O} \mathrm{pH}$ do extrato aquoso bruto (100\%) de folhas verdes de girassol foi 7,34. Neste caso, como o $\mathrm{pH}$ do extrato a $100 \%$ estava neutro e as diluições foram feitas em água destilada os outros extratos também apresentaram pH neutro. Informações disponíveis na literatura ressaltam que ocorrem efeitos do $\mathrm{pH}$ sobre a germinação e o desenvolvimento de plântulas apresentam-se em meios extremamente ácidos ou alcalinos, sendo recomendado o uso de um $\mathrm{pH}$ na faixa de 6,0 a 7,5 para experimentos em laboratório (FILHO; RODRIGUES; RODRIGUES, 1997; FILHO; DUTRA, 2007; KERBAUY, 2004).

Larcher (2000) ressalta que valores de $\mathrm{pH}$ na faixa entre 6,0 - 7,5 favorecem os processos bioquímicos e a nutrição vegetal. Assim, considerando o valor do $\mathrm{pH}$ dos extratos aquosos de folhas verdes de girassol, pode-se concluir que este parâmetro está fora da faixa que poderia afetar a germinação ou o desenvolvimento inicial das espécies em estudo.

A porcentagem de germinação das sementes da cultivar CD232 (soja convencional) foi reduzida quando aplicado as maiores concentrações do extrato aquoso (80 e 100\%) (Tabela 1). Por outro lado, no tempo médio e na velocidade média de germinação não houve diferença entre a testemunha e as demais concentrações do extrato aplicado.

Assim como os resultados da cultivar CD232, sementes de mostarda (Sinapis alba L.) também sofreram inibição na porcentagem de germinação quando submetidas ao extrato aquoso da parte aérea do girassol (KUPIDLOWSKA et al., 2006).

Para a cultivar CD213RR (soja transgênica) foi observada diferença significativa na variável porcentagem de germinação entre as sementes da testemunha e as submetidas à maior concentração do extrato aquoso de girassol (100\%), coincidindo com o maior tempo médio de germinação. Já a velocidade média de germinação foi reduzida na presença do extrato a $40 \%$ (Tabela 1$)$. 
Tabela 1. Efeito alelopático do extrato aquoso de folhas frescas de girassol (Helianthus annuus L.) sobre a porcentagem de germinação (PG\%), tempo médio de germinação (TMG), velocidade média de germinação (VMG) e comprimento médio de raiz (CMR), de sementes de soja convencional (Glycine max L. Merril), cultivar CD232 e soja transgênica (Glycine max L. Merril), cultivar CD213RR.

\begin{tabular}{|c|c|c|c|c|c|c|c|c|}
\hline \multirow[t]{2}{*}{ Tratamentos } & \multicolumn{2}{|c|}{$\begin{array}{l}\mathrm{PG} \\
(\%)\end{array}$} & \multicolumn{2}{|c|}{$\begin{array}{l}\text { TMG } \\
\text { (dias) }\end{array}$} & \multicolumn{2}{|c|}{$\begin{array}{c}\text { VMG } \\
\text { (sementes/ dia) }\end{array}$} & \multicolumn{2}{|c|}{$\begin{array}{l}\text { CMR } \\
(\mathrm{cm})\end{array}$} \\
\hline & CD232 & CD213RR & CD232 & CD213RR & CD232 & CD213RR & CD232 & CD213RR \\
\hline Testemunha & $86 \mathrm{~A}$ & $94 \mathrm{a} A$ & $2,55 \mathrm{aA}$ & $2,03 \mathrm{~b} \mathrm{~B}$ & $0,39 \mathrm{a} B$ & $0,49 \mathrm{a} \mathrm{A}$ & $11,43 \mathrm{a}$ B & $14,22 \mathrm{a} \mathrm{A}$ \\
\hline Extrato a $20 \%$ & $84 \mathrm{ab} \mathrm{A}$ & $90 \mathrm{ab} A$ & $2,56 \mathrm{a} A$ & $1,98 \mathrm{~b} \mathrm{~B}$ & $0,39 \mathrm{a} B$ & $0,50 \mathrm{a} A$ & $9,98 \mathrm{a} \mathrm{B}$ & $13,31 \mathrm{a} \mathrm{A}$ \\
\hline Extrato a $40 \%$ & $87 \mathrm{a} \mathrm{A}$ & $91 \mathrm{ab} A$ & $2,88 \mathrm{a} \mathrm{A}$ & $2,20 \mathrm{~b} \mathrm{~B}$ & $0,35 \mathrm{a} A$ & $0,46 \mathrm{~b} \mathrm{~A}$ & $10,44 \mathrm{a} A$ & $10,59 \mathrm{~b} \mathrm{~A}$ \\
\hline Extrato a $60 \%$ & $75 \mathrm{abc} B$ & $86 a b \mathrm{~A}$ & $3,03 \mathrm{a} \mathrm{A}$ & $2,63 \mathrm{ab} \mathrm{A}$ & $0,33 \mathrm{a} A$ & $0,38 \mathrm{~b} \mathrm{~A}$ & $6,52 \mathrm{~b} \mathrm{~A}$ & $7,53 \mathrm{c} \mathrm{A}$ \\
\hline Extrato a $80 \%$ & $65 \mathrm{c} \mathrm{B}$ & $86 a b \mathrm{~A}$ & $3,16 \mathrm{a} A$ & $3,21 \mathrm{ab} \mathrm{A}$ & $0,32 \mathrm{aA}$ & $0,31 \mathrm{~b} \mathrm{~A}$ & $4,45 b c \mathrm{~B}$ & $7,72 \mathrm{c} \mathrm{A}$ \\
\hline Extrato a $100 \%$ & $72 \mathrm{bc} \mathrm{B}$ & $81 \mathrm{~b} \mathrm{~A}$ & $3,15 \mathrm{a} B$ & $3,88 \mathrm{a} \mathrm{A}$ & $0,32 \mathrm{a} \mathrm{A}$ & $0,28 \mathrm{~b} \mathrm{~A}$ & $3,67 \mathrm{c} \mathrm{B}$ & $7,46 \mathrm{c} \mathrm{A}$ \\
\hline Extrato & \multicolumn{2}{|c|}{$9,332 * *$} & \multicolumn{2}{|c|}{$5,982 * *$} & \multicolumn{2}{|c|}{$4,543 * *$} & \multicolumn{2}{|c|}{$76,719^{* *}$} \\
\hline Cultivar & \multicolumn{2}{|c|}{$31,736^{* *}$} & \multicolumn{2}{|c|}{$4,455 * *$} & \multicolumn{2}{|c|}{$10,714 * *$} & \multicolumn{2}{|c|}{$74,064 * *$} \\
\hline Extrato x Cultivar & \multicolumn{2}{|c|}{$2,115 \mathrm{~ns}$} & \multicolumn{2}{|c|}{$3,8^{*}$} & \multicolumn{2}{|c|}{$4,543 * *$} & \multicolumn{2}{|c|}{$3,902 * *$} \\
\hline C.V $(\%)$ & \multicolumn{2}{|c|}{7,17} & \multicolumn{2}{|c|}{17,28} & \multicolumn{2}{|c|}{21,16} & \multicolumn{2}{|c|}{11,12} \\
\hline
\end{tabular}

Médias seguidas de mesma letra minúsculas na coluna e maiúsculas na linha para cada variável, não diferem significativamente entre si pelo teste de Tukey, a 5\% de probabilidade.

Este resultado está de acordo com o que foi relatado por Ferreira (2004), o qual afirma que a porcentagem final de germinação normalmente é menos influenciada pela presença dos compostos alelopáticos em baixas concentrações enquanto o tempo médio e a velocidade média de germinação são mais sensíveis, resultando em alterações na curva de germinação.

Outra característica influenciada pelo extrato aquoso é o comprimento médio de raiz, que foi inibido na soja transgênica quando utilizouse o extrato aquoso na concentração de $40 \%$, confirmando assim as informações fornecidas por Ferreira (2004).

A análise de variância da interação entre a aplicação das diferentes concentrações do extrato aquoso e as cultivares de soja foi significativa para todas as variáveis analisadas. Para a porcentagem de germinação e comprimento médio de raiz, fica evidente que a cultivar CD213RR resiste melhor à ação alelopática exercida pelo extrato aquoso das folhas de girassol, pois esta cultivar apresentou maiores porcentagens de germinação e comprimento médio de raiz em relação à cultivar CD232 em todas as concentrações do extrato aplicado (Tabela 1).

Para as variáveis tempo médio e velocidade média de germinação, as diferenças entre as cultivares também foram observadas. O tempo médio de germinação na cultivar CD213RR foi menor, se comparada com a cultivar CD232 na testemunha e nas concentrações de $20 \%, 40 \%$ e $60 \%$ do extrato. A velocidade média de germinação para a cultivar CD213RR foi maior quando comparada com a cultivar CD232 na testemunha e na concentração de $20 \%$ do extrato (Tabela 1), demonstrando que as cultivares de soja utilizadas neste trabalho respondem de forma diferente quando submetidas à mesma situação.

Porém, esta diferença entre as cultivares na presença dos aleloquímicos não foi verificada por Roncatto e Viecelli (2009), ao estudarem o efeito alelopático dos resíduos de diferentes partes do girassol na germinação e no desenvolvimento inicial de dois híbridos de milho ( $B t$ e convencional). Os resultados desse trabalho mostraram que a germinação e o comprimento da parte aérea dos 
híbridos de milho foram inibidos nas menores concentrações de aleloquímicos, enquanto o comprimento de raiz foi reduzido nas maiores concentrações.

Estudos desenvolvidos por Bernat et al. (2004) demonstraram que o extrato aquoso da parte aérea do girassol também reduz a germinação e/ou desenvolvimento de espécies cultivadas como a mostarda e o trigo. Porém, fica claro que a forma como uma espécie ou cultivar responde à presença dos aleloquímicos no meio varia, podendo algumas espécies como é o caso do trigo, expressar maior resistência à ação alelopática do girassol (BERNAT et al., 2004; ALMEIDA, 1990). Este fato também pode ser verificado ao se comparar os resultados deste experimento para a soja convencional (CD232) e a soja transgênica (CD213RR).
Mesmo com a inibição das variáveis analisadas para as sementes de soja na presença do extrato aquoso de folhas verdes de girassol, deve-se levar em consideração que esta inibição ocorreu em concentrações elevadas $(60 \%, 80 \%$ e $100 \%$, dependendo da variável) e em condições de campo a intensidade deste efeito pode variar, pois, segundo Almeida (1988) é comum que a presença de microorganismos no solo promova a degradação dos metabólitos secundários liberados pelos vegetais, reduzindo assim sua concentração no meio.

Quanto aos resultados obtidos para as sementes de picão preto, pode-se verificar que a presença da concentração do extrato aquoso do girassol (20\%) inibiu a porcentagem de germinação, havendo diferença significativa entre este tratamento e a testemunha (Tabela 2).

Tabela 2. Efeito alelopático do extrato aquoso de folhas frescas de girassol (Helianthus annuus L.) sobre a porcentagem de germinação (PG\%), tempo médio de germinação (TMG), velocidade média de germinação (VMG) e comprimento médio de raiz $(\mathrm{CMR} \mathrm{cm})$ de sementes de picão preto (Bidens pilosa $\mathrm{L}$.)

\begin{tabular}{lcccc}
\hline \multicolumn{1}{c}{ Tratamentos } & $\begin{array}{c}\text { PG } \\
(\%)\end{array}$ & $\begin{array}{c}\text { TMG } \\
\text { (dias) }\end{array}$ & $\begin{array}{c}\text { VMG } \\
\text { (sementes/dia) }\end{array}$ & $\begin{array}{c}\text { CMR } \\
(\mathrm{cm})\end{array}$ \\
\hline Testemunha & $76 \mathrm{a}$ & $3,44 \mathrm{a}$ & $0,29 \mathrm{a}$ & $1,96 \mathrm{a}$ \\
Extrato a $20 \%$ & $24 \mathrm{~b}$ & $6,25 \mathrm{~b}$ & $0,09 \mathrm{~b}$ & $0,32 \mathrm{~b}$ \\
Extrato a $40 \%$ & $0 \mathrm{c}$ & $0 \mathrm{~b}$ & $0 \mathrm{c}$ & $0 \mathrm{~b}$ \\
Extrato a $60 \%$ & $0 \mathrm{c}$ & $0 \mathrm{~b}$ & $0 \mathrm{c}$ & $0 \mathrm{~b}$ \\
Extrato a $80 \%$ & $0 \mathrm{c}$ & $0 \mathrm{~b}$ & $0 \mathrm{c}$ & $0 \mathrm{~b}$ \\
Extrato a $100 \%$ & $0 \mathrm{c}$ & $0 \mathrm{~b}$ & $0 \mathrm{c}$ & $0 \mathrm{~b}$ \\
\hline C.V\%. & 47,81 & 15,13 & 41,33 & 68,04 \\
\hline
\end{tabular}

Médias seguidas de mesma letra não diferem significativamente entre si pelo teste de Tukey, a 5\% de probabilidade.

Também foi constatada diferença para o tempo médio, velocidade média de germinação e comprimento médio de raiz das plântulas de picão preto. Além disso, quando as sementes de picão preto foram submetidas a concentração de $40 \%$ do extrato, a porcentagem de germinação das mesmas foi completamente inibida.

Resultados semelhantes foram encontrados por Anjum et al. (2004), ao estudarem o potencial alelopático do girassol sobre cinco espécies vegetais invasoras do cultivo de trigo, Phalaris minor, Chenopodium album, Coronopis didymus, Rumex dentatus e Medicago polymorpha, em que se observou redução no peso seco das plântulas invasoras quando aplicado o extrato aquoso da parte aérea do girassol a $10 \%$.

Vale ressaltar que dentre as substâncias presentes nas folhas de girassol com efeito alelopático comprovado estão os terpenos, maior grupo de metabólitos secundários existente, os quais são 
substâncias insolúveis em água (TAIZ; ZEIGER, 2009). Isso indica que neste experimento os terpenos podem não terem sido os responsáveis pelo expressivo efeito inibitório do girassol sobre as sementes de picão preto, enquanto outras substâncias presentes nas folhas do girassol, como os flavonóides (substâncias solúveis em água) podem ter sido os responsáveis por esse efeito.

Para comprovar que o extrato aquoso de folhas verdes de girassol apresenta efeito alelopático sobre as espécies estudadas, sugerem-se estudos a campo para verificação da intensidade desse efeito.

\section{Conclusão}

O girassol apresenta efeito inibidor sobre as sementes de picão preto, pois o extrato aquoso na concentração a partir de $40 \%$ inibiu a germinação desta espécie.

\section{Referências}

ALMEIDA, F. S. A Alelopatia e as plantas. Londrina: IAPAR, 1988. 60 p. (Circular, n. 53).

. A Defesa das plantas. Ciência Hoje, São Paulo, v. 11, n. $62,1990$.

Efeitos alelopáticos de resíduos vegetais. Pesquisa Agropecuária Brasileira, Brasília, v. 26, n. 2, p. 221-236, fev. 1991.

ANJUM, T.; STEVENSON, P.; HALL, D.; BAJWA, R. 2004 Allelopathic potential of Helianthus annuus $L$. (sunflower) as natural herbicide. Disponível em: $<\mathrm{http}: / /$ www.regional.org.au/au/allelopathy/2005/2/7/2252anju,.htm>. Acesso em: 13 mar. 2007.

BERNAT, W.; GAWRONSKA, H.; JANOWIAK, F.; GAWRONSKI, S. W. The effect of sunflower allelopathycs on germination and seedling vigour of winter wheat and mustard. Zeszyty Problemowe Postepow Nauk Rolniczych, Polska Academia Nauk, v. 496, n. 1, p. 289-300, 2004.

BHOWMIK, P. C.; INDERJIT. Challenges and opportunities in implementing allelopathy for natural weed management. Crop Protection, Oxford, v. 22, n. 4, p. 661-671, maio 2003.
BRASIL. Ministério da Agricultura. Regra de análise de sementes. Brasília: Departamento de Produção Vegetal, 1992.

CARMO, F. M. D. S.; FERREIRA, K. M. Princípios básicos em alelopatia. In: CONGRESSO NACIONAL DE BOTÂNICA, 55., ENCONTRO REGIONAL DE BOTÂNICOS, 26., 2004, Viçosa. Anais...Viçosa: Universidade Federal de Viçosa, 2004, p. 2-10.

CARVALHO, A. M. Como rotacionar cultivos: na escolha dos cultivos, deve-se compatibilizar produção de grãos, biomassa e cobertura do solo. DBO Agrotecnologia, São Paulo, v. 1, n.1, p. 30-31, nov. 2006.

CASTRO, C.; CASTIGLIONI, V. B. R.; BALLA, A.; LEITE, R. M. V. B. C.; KARAM, D.; MELLO, H. C.; GUEDES, L. C. A.; FARIAS, J. R. B. A. Cultura do girassol. Londrina: EMBRAPA, 1997. 36 p. (Circular técnica, n. 13).

EDMOND, J. B.; DRAPALA, W. J. The effects of temperature, sand and soil, and acetone on germination of okra seed. Proceedings of the American Society for Horticultural Science, Alexandria, v. 71, n. 2, p. 428-443, 1958.

EMPRESA BRASILEIRA DE PESQUISA AGROPECUÁRIA - EMBRAPA RORAIMA. O girassol como alternativa de combustivel. 2005. Disponível em: <http://www.cpafrr.embrapa.br/index.php/cpafrr/ artigos/o_girassol_como_alternatica_de_combust_vel $>$ Acesso em: 15 dez. 2006.

FERREIRA, A. G. Interferência: competição e alelopatia, In: FERREIRA, A. G.; BORGHETTI, F. Germinação do básico ao aplicado. Porto Alegre: Artmed, 2004. cap. 16.

FERREIRA, G. A.; AQUILA, M. E. A. Alelopatia: uma área emergente na ecofisiologia. Revista Brasileira de Fisiologia Vegetal, Campinas, v. 12, p.175-204, 2000. Edição Especial.

FILHO, A. P. S.; DUTRA, S. Germinação de sementes de calopogônio (Calopogonium mucunoides). Pasturas tropicales, 2000. v. 20, n. 3. Disponível em: http://ciatlibrary.ciat.cgiar.org/Articulos_Ciat/ PAST2035.pdf. Acesso em: 13 out. 2007.

FILHO,A.P. S.; RODRIGUES,A.L. R.A.; RODRIGUES, T. J. D. Efeito do potencial alelopático de três leguminosas forrageiras sobre três invasoras de pastagens. Pesquisa Agropecuária Brasileira, Brasília, v. 32, n. 2, p. 165-170, fev. 1997.

HADAS, A. Water update germination of leguminous seeds under changing external water potential in osmotic solution. Journal Experimental of Botany, Oxford, v. 27, n. 98, p. $480-489,1976$. 
HOFFMANN, L. L.; REIS, E. M.; FORCELINI, C. A.; PANISSON, E.; MENDES, C. S.; CASA, R. T. Efeitos da rotação de cultura, de cultivares e da aplicação de fungicida sobre o rendimento de grãos e doenças foliares em soja. Fitopatologia Brasileira, Brasília, v. 29, n. 3, p. 245-251, maio/jun. 2004.

KERBAUY, G. B. Fisiologia vegetal. Rio de Janeiro: Guanabara Koogan, 2004. 472 p.

KUPIDLOWSKA, E.; GNIAZDOWSKA, A.; STEPIEN, J.; CORBINEAU, F.; VINEL, D.; SKOCZOWSKI, A.; JANECZKO, A.; BOGATEK, R. Impact of sunflower (Helianthus annuus $\mathrm{L}$.) extracts upon reserve mobilization and energy metabolism in germinating mustard (Sinapis alba L.) seeds. Journal Chemical of Ecology, New York, v. 32, n. 12, p. 2569-2583, 2006.

LABORIAU, L. G. A Germinação das sementes. Washington: Organização dos Estados Americanos, 1983. (Monografia, 24).

LARCHER, W. Ecofisiologia vegetal. São Carlos: Rima, 2000.

MONTEIRO, C. A.; VIEIRA, R. A. Substâncias alelopáticas. In: CASTRO, P. R. C.; SENA, J. O. A.; KLUGE, R. A. Introdução à fisiologia do desenvolvimento vegetal. Maringá: EDUEM, 2002.
PASQUALETO, A.; COSTA, L. M.; SILVA, A. A.; SEDIYMA, C. S. Ocorrência de plantas daninhas na cultura da soja (Glycine max (L.) Merrill) em sucessão à culturas de safrinha no sistema plantio direto. 2007. Disponível em: http://agata.ucg.br/formularios/ucg/ docentes/eng/pasqualeto/artigos/pdf/artigo_48. pdf. Acesso em: 30 mar. 2007.

PELEGRINI, B. Girassol: uma planta solar que das Américas conquistou o mundo. São Paulo: Ícone, 1985.

PIMENTEL-GOMES, F. Curso de estatística experimental. São Paulo: Nobel, 1990.

PRIMAVESI, A. Revisão do conceito de agricultura orgânica: conservação do solo e seu efeito sobre a água. O Biológico, São Paulo, v. 65, n. 1/2, p. 69-73, jan./dez. 2003.

PRIMAVESI, A. M. A Agricultura em regiões tropicais: manejo ecológico do solo. São Paulo: Nobel, 1986. 536 p.

RONCATTO, F.; VIECELLI, C.A. Adubação verde de girassol sobre o desenvolvimento do milho. Cultivando o saber, Cascavel, v. 2, n. 3, p. 1-6, 2009.

TAIZ, L. ZEIGER, E. Fisiologia vegetal. 4. ed. Porto Alegre: Artmed, 2009. 